\title{
Remote Sensing of Sea Surface Salinity From CAROLS L-Band Radiometer in the Gulf of Biscay
}

\author{
Adrien Martin ${ }^{1}$, Jacqueline Boutin ${ }^{1}$, Danièle Hauser ${ }^{2}$, Gilles Reverdin ${ }^{1}$, Mickaël Pardé ${ }^{2}$, Mehrez Zribi ${ }^{3}$, \\ Pascal Fanise ${ }^{2}$, Jérôme Chanut ${ }^{4}$, Pascal Lazure ${ }^{5}$, Joseph Tenerelli ${ }^{6}$, and Nicolas Reul ${ }^{5}$
}

\footnotetext{
1 Institut Pierre-Simon Laplace, Laboratoire d'Océanographie et du Climat Expérimentation et Ap- proches Numériques (LOCEAN), Unité Mixte de Recherche 7159 Université Pierre et Marie Curie-Centre National de la Recherche Scientifique-Institut de Recherche pour le Développement-Muséum National d'Histoire Naturelle, 75252 Paris, France

2 Université de Versailles Saint-Quentin en Yvelines, and CNRS, in Laboratoire Atmosphères, Milieux, Observations Spatiales (LATMOS) from Institut Pierre-Simon Laplace, 78280 Guyancourt, France

${ }^{3} \mathrm{CESBIO}$ (CNRS/IRD/UPS/CNES), 31000 Toulouse, France

${ }^{4}$ Mercator, 31000 Toulouse, France

5 Institut Français de Recherche pour l'Exploitation de la Mer (IFREMER), 29280 Plouzané, France

${ }^{6}$ CLS, 29280 Plouzané, France

*: Corresponding author : A. Martin, email address : amlod@locean-ipsl.upmc.fr
}

\begin{abstract}
:
A renewal of interest for the radiometric L-band Sea Surface Salinity (SSS) remote sensing appeared in the 1990s and led to the Soil Moisture and Ocean Salinity (SMOS) satellite launched in November 2009 and to the Aquarius mission (launched in June 2011). However, due to low signal to noise ratio, retrieving SSS from L-band radiometry is very challenging. In order to validate and improve L-band radiative transfer model and salinity retrieval method used in SMOS data processing, the Cooperative Airborne Radiometer for Ocean and Land Studies (CAROLS) was developed. We analyze here a coastal flight (20 May 2009), in the Gulf of Biscay, characterized by strong SSS gradients (28 to 35 pss-78). Extensive in-situ measurements were gathered along the plane track. Brightness temperature $\$\left(T \_\{b\}\right) \$$ integrated over $800 \mathrm{~ms}$ correlates well with simulated \$T_\{b\}\$ (correlation coefficients between 0.80 and 0.96 ; standard deviations of the difference of $0.2 \bar{K}$ ). Over the whole flight, the standard deviation of the difference between CAROLS and in-situ SSS is about 0.3 pss-78 more accurate than SSS fields derived from coastal numerical model or objective analysis. In the northern part of the flight, CAROLS and in-situ SSS agree. In the southern part, the best agreement is found when using only $V$-polarization measured at $30 \$^{\wedge}\{$ circ $\} \$$ incidence angle or when using a multiparameter retrieval assuming large error on \$T_\{b\}\$ (suggesting the presence of biases on $\mathrm{H}$ polarization). When compared to high-resolution model SSS, the CAROLS SSS underlines the high SSS temporal variability in river plume and on continental shelf border, and the importance of using realistic river run-offs for modeling coastal SSS.
\end{abstract}

Keywords: L-band, microwave radiometry, remote sensing, retrieval method, sea surface salinity (SSS), Soil Moisture and Ocean Salinity (SMOS), wind speed 


\section{Introduction}

Sea surface salinity (SSS) is a key component of the global earth water cycle and of the ocean circulation. Through its link to the evaporation minus precipitation budget, the SSS can provide valuable estimations of the freshwater flux, one of the less known components of the earth's water cycle [1]-[3]. Generally the focus is on the water cycle over the land, but as $86 \%$ of the evaporation and $78 \%$ of the precipitation occurs over the ocean, these fluxes cannot be ignored for our understanding of "the global water cycle" [4]. SSS is a driving force for the thermohaline circulation and is therefore fundamental for our understanding of processes that force our global climate system. Moreover, SSS is a better tracer than sea surface temperature (SST) to track water masses as SST varies rapidly with atmospheric conditions. In-situ measurements of ocean salinity remain scarce, despite the deployment of Array for Real-time Geostrophics Oceanography (ARGO) floats [5] and the multiplication of measurements on voluntary ships. Indeed, sampling remains irregularly and nonhomogeneously distributed and mostly limited to the range from 5 to $10 \mathrm{~m}$ below the surface. The ability to monitor SSS for years from satellite would be a significant improvement for the understanding and the prediction of meteorological and climate phenomena [6]. The principle of satellite SSS remote sensing has been thoroughly described [7], [8]. At L-band $(1.4 \mathrm{GHz})$, the permittivity of the sea surface is significantly affected by the salinity. Hence, sea surface emissivity and then brightness temperature can be related to SSS. The concept of microwave SSS remote sensing has been demonstrated in the late 1970s with Skylab [9] and by the first airborne L-band microwave systems [10], [11]. At the end of the 1990s, two airborne microwave interferometers, the Electronically Scanned Thinned Array Radiometer (ESTAR) and the Scanning Low-Frequency Microwave Radiometer (SLFMR), successfully produced SSS maps in coastal currents [8], [12], [13] in agreement with in-situ measurements with an accuracy of about 1 pss-78.1 More recently, the Salinity, Temperature, and Roughness Remote Scanner (STARRS) used a $8 \times 8$ antenna array which operated interferometrically and provided noisier measurements than real aperture radiometer $(1 \mathrm{~s}-$ NEDT of $0.9 \mathrm{~K}$ ) [15]. In spite of this, it was proven to be useful for mapping SSS in the vicinity

${ }^{1}$ pss-78 stands for Pratical Salinity Scale (1978) defined from a conductivity ratio [14]. 
This article has been accepted for inclusion in a future issue of this journal. Content is final as presented, with the exception of pagination.

of Rio de la Plata Estuary and Patos/Mirim outflows, in complement to in-situ measurements and for characterizing the dynamic of the plumes [16]. A new interferometer was developed by the Helsinki University of Technology with similar characteristics to that of MIRAS installed onboard Soil Moisture and Ocean Salinity (SMOS) [3], [17]. Data collected in the Gulf of Finland indicated the need for external calibration and an rms (root mean square) error on the retrieved SSS of about 2 pss-78 [18].

Taking into account the successful airborne measurements of SSS, and the improvement of the technology [8], the European Space Agency decided to build and launch the SMOS satellite mission [3], [19], [20]. SMOS is the first L-band satellite able to provide SSS measurements at global scale. It uses a very innovative interferometric technology and was successfully launched on November 2, 2009. Its aim is to achieve an accuracy on retrieved salinity of 0.1 pss-78, over (100-200 km, 10-30 days time and space scales) relevant to climatic studies. In addition to SMOS, another L-band satellite instrument dedicated to measure SSS was launched on June 9, 2011 with the Aquarius/SAC-D [21] mission.

However, getting this accuracy on SSS from L-band radiometry requires a very good knowledge of the influence of other parameters that affect the L-band measured signal. For that reason, the Cooperative Airborne Radiometer for Ocean and Land Studies (CAROLS) [22] was developed and operated for various airborne campaigns from 2007 to 2010, in order to validate and improve models used in the SMOS data processing for salinity retrieval.

This paper focuses on a flight on May 20, 2009, over a coastal region in the Gulf of Biscay (South-West of France and North of Spain) which is characterized by a high salinity variability ( 28 to 35 pss-78). The objectives of this study are to retrieve the SSS from the airborne CAROLS observations and to determine the influence of spatio-temporal variability of the sea surface roughness (parameterized as a function of wind speed) on this retrieval using the same direct models and similar retrieval methodology as those defined and used for SMOS.

In Section II, we present the radiometer data acquired using CAROLS and the corresponding sea surface parameters measured in situ. Then, in Section III, we describe the methods used to simulate brightness temperatures and to retrieve SSS. In Section IV, we present results on the retrieved SSS from CAROLS measurements and compare them to in-situ measurements. Key results from this study are summarized and discussed in Section V.

\section{DATA}

\section{A. CAROLS Radiometric Data}

The CAROLS L-band radiometer [22] was designed and built as a copy of the EMIRAD II radiometer [23] constructed by the Danish Technical University team. It is a fully polarimetric and direct sampling correlation radiometer (sampling rate of $139.4 \mathrm{MHz}$ ). The antenna system comprises two identical horns and two waveguide orthomode transducers with a main
TABLE I

SENSITIVITY TO PARAMETERS FOR NADIR AND $30^{\circ}$ ANTENNAS IN H AND V POLARIZATION

\begin{tabular}{c|c|cc}
\hline & Nadir & \multicolumn{2}{|c}{$30^{\circ}$} \\
& $\mathrm{H}$ or $\mathrm{V}$ & $\mathrm{H}$ & $\mathrm{V}$ \\
\hline Incidence angle $\left(\mathrm{K} /{ }^{\circ}\right)$ & \pm 0.05 & -0.7 & 1.2 \\
Wind Speed at $7 \mathrm{~m} / \mathrm{s}\left(\mathrm{K} / \mathrm{ms}^{-1}\right)$ & 0.21 & 0.30 & 0.17 \\
SSS $(\mathrm{K} / \mathrm{pss}-78)$ & -0.47 & -0.41 & -0.52 \\
\hline
\end{tabular}

lobe of $37^{\circ}$ half-power beam width. One antenna looks at the nadir and the other points at $33^{\circ}$ on the right-hand side (referred to as the $30^{\circ}$ antenna in the following) of the aircraft (French research ATR42 airplane). Brightness temperatures $\left(T_{b}\right)$ of the surface were measured using these two antennas. The aircraft contains an inertial unit (a SAGEM sampling at $25 \mathrm{~Hz}$ ) to measure aircraft movements and to deduce the incidence angle of the antennas with the sea surface. Indeed, the $T_{b}$ is highly dependent on the incidence angle, about $1 \mathrm{~K} /{ }^{\circ}$ at $30^{\circ}$ incidence angle (see [24] and Table I).

CAROLS flew seven times over the Gulf of Biscay, off the coast of France and Spain, between May 04 and May 26, 2009 around 20 UTC. These flights followed two other airborne campaigns with the same instrument in September 2007 and November 2008 both conducted in the Gulf of Biscay. Most of these flights were performed at high altitude far from land. In this paper, we concentrate on a flight performed at low altitude in a coastal area with strong SSS contrast.

The aircraft flew about $600 \mathrm{~m}$ above the sea at an airspeed of about $100 \mathrm{~m} / \mathrm{s}$. The main lobe of the instrument footprint covers an elliptical area with major and minor semiaxes of $200 \mathrm{~m}$ for the Nadir antenna and of $300 \mathrm{~m}$ and $240 \mathrm{~m}$ for the $30^{\circ}$ antenna. The boresight of the two antennas are $390 \mathrm{~m}$ apart.

The radiometer measures the four Stokes parameters alternatively on the two antennas. A sequence of acquisition includes the following steps: an internal calibration on a load and a noise diode during $10 \mathrm{~s}$ followed during $120 \mathrm{~s}$ by 60 alternative measurements of $2 \mathrm{~s}$ duration between the nadir antenna ( $800 \mathrm{~ms})$, the noise diode (200 ms), the slant antenna (800 ms) and the noise diode (200 ms). The raw data sampling is of $40 \mathrm{~ms}$ with a theoretical noise on $T_{b}$ of $0.26 \mathrm{~K}$ (we have checked that this agrees with noise observed on measurements acquired on another CAROLS flight on May 26, 2009 in uniform geophysical conditions in the open ocean far from the coast). It is known that radiometers at L-band are very sensitive to parasitic signals from radio-frequency interferences (RFI) [25]-[27]. Despite the CAROLS bandwidth has been limited to $24 \mathrm{MHz}$ since 2008 (instead of $26 \mathrm{MHz}$ before [22]), we still observe RFI during all flights, although they are of much lesser magnitude than before 2008. Therefore, we used a specific method to sort out observations possibly perturbed by RFI (see below).

The full postprocessing applied on the raw data consists of:

- Correcting for cable attenuation and reflexion [22].

- Removing measurements likely affected by RFI. A kurtosis threshold criterium is applied (kurtosis larger than 2.9-3.1 calculated on the integration time of $1 \mathrm{~ms}$ ) to detect cases of non-Gaussian signal distribution and reject the main part of RFI [27]. Less than $2 \%$ of data over ocean flights are rejected due to RFI. 


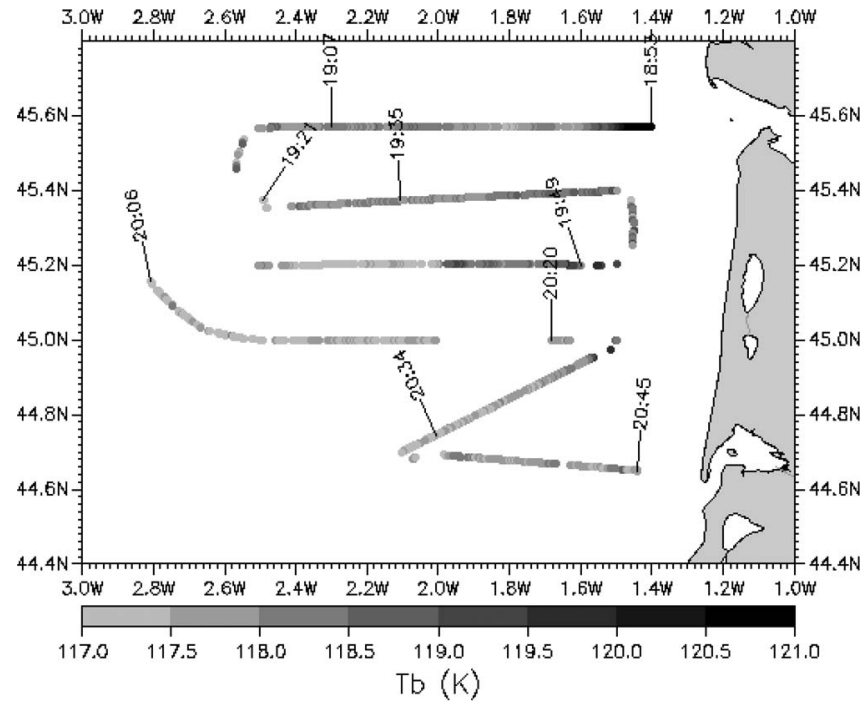

Fig. 1. Brightness temperature in V-polarization by the $30^{\circ}$ CAROLS antenna after postprocessing (see text).

- Removing measurements corresponding to incidence angles outside the range of $0^{\circ}-2^{\circ}$ and $33.4^{\circ}-35.5^{\circ}$ for the nadir and the $30^{\circ}$ incidence antenna, respectively.

- Post-integrating data for each antenna and polarization over $2 \mathrm{~s}$ time interval corresponding to up to 20 samples $(800 \mathrm{~ms} / 40 \mathrm{~ms})$ per antenna. Due to data rejection explained above, this number may vary between 0 and 20 samples and we reject data with less than 10 samples. Therefore, the final theoretical noise of the processed data is between $0.08 \mathrm{~K}(0.26 / \sqrt{10})$ and $0.06 \mathrm{~K}(0.26 / \sqrt{20})$.

After these processings, two periods (20:17:30 to 20:21:50 and 20:22:45 to 20:24:35) remain during which higher discrepancies between the $\mathrm{V}$ and $\mathrm{H}$ polarization measured for the Nadir antenna are observed. Indeed, the standard deviation of the difference between measurements in $\mathrm{V}$ and $\mathrm{H}$ polarization is of $0.25 \mathrm{~K}$ during these periods whereas for the rest of the flight it is of $0.1 \mathrm{~K}$. Since this occurs when the airplane was close to the Cazaux coastal region identified as a source of RFI on CAROLS data [25] and on SMOS data [28], we suspect it could be due to undetected RFI.

The final product is shown in Fig. 1 for the V-Polarization of the $30^{\circ}$ antenna. This instrumental configuration corresponds to the highest sensitivity to salinity (Table I) with $T_{b}$ values over the ocean ranging from $114 \mathrm{~K}$ to $122 \mathrm{~K}$. Highest values of $T_{b}$ are observed at the beginning of the flight near the Gironde outflow $(45.6 \mathrm{~N}, 1.4 \mathrm{~W})$, consistent with a smaller salinity in this region due to the fresh water outflow. Circles and wingwags have been performed at different places along the track but are not considered in the present analysis. The L-band sensitivity to geometrical and geophysical parameters are summarized in (Table I). They are deduced from the model presented below.

\section{B. Sea Surface Conditions}

The knowledge of sea surface conditions is an important element to evaluate accuracy of the radiometric measurements and to validate the radiative transfer models. Indeed, the L-band signal is sensitive to SSS but also to SST and sea surface roughness, which is primarily parameterized through wind speed. In order to document the sea surface conditions during the flights, the GOGASMOS oceanic campaign was organized. The RV Antea operated on the Aquitaine shelf [Figs. 2(a) and 3(b)] and performed SSS measurements continuously using a SeaBird SBE-21 thermosalinograph (TSG); the water intake was approximately at $3.5-\mathrm{m}$ depth. These data were corrected for biases and validated by comparison with samples, sensors calibrations and comparison with nearby data. The accuracy of these data is estimated to be within a few 0.01 pss-78 [29]. The RV Antea monitored the SSS under most of the plane track. The monitoring under the plane track begins [see Fig. 2(a)] on May 20th at $17 \mathrm{UTC}$ at $44.68 \mathrm{~N}-2.12 \mathrm{~W}$. It continues northeast to $45.0 \mathrm{~N}-1.5 \mathrm{~W}$. The vessel was overflown by the airplane at 20:28:30 $(44.89 \mathrm{~N}-1.69 \mathrm{~W})$; the corresponding sea surface conditions as measured in situ are summarized in (Table II). After this north-east section, the vessel completes a track at $45.0 \mathrm{~N}$ until $2.5 \mathrm{~W}$, joins the track at $45.2 \mathrm{~N}$, and heads to $1.5 \mathrm{~W}$. It then joins the track at $45.4 \mathrm{~N}$, heads westward to $2.5 \mathrm{~W}$, and finishes south-westward up to $45.06 \mathrm{~N}-2.64 \mathrm{~W}$ on May 21th at 18UTC.

Moreover, in the frame of the GOGASMOS campaign, a mooring was installed at $45.56 \mathrm{~N}-1.83 \mathrm{~W}$ and acquired measurements every $30 \mathrm{~s}$ at $2 \mathrm{~m}$ depth with an accuracy of a few 0.01 pss-78.

In addition to this dedicated campaign, we also use measurements performed nearby during two other campaigns. The RV Investigador from AZTI-Tecnalia performed CTD vertical profiles on the track $45.62 \mathrm{~N}$ [see Fig. 2(a)]. It begins at $2.85 \mathrm{~W}$ (May 19, 14UTC) eastward and finishes at $1.43 \mathrm{~W}$ (May 20, 01UTC), i.e., about one day before the flight. As the temperature sensor had a $1 \mathrm{~s}$ time constant, the accuracy of these measurements is about 0.1 pss-78 [29]. Only measurements closest to the surface (about $3 \mathrm{~m}$ ) were taken into account.

Two water samples were taken under the plane track during the Arcadino campaign at $44.65 \mathrm{~N}-1.43 \mathrm{~W}, 18 \mathrm{UTC}$ and $44.49 \mathrm{~N}-$ $1.39 \mathrm{~W}, 19: 50 \mathrm{UTC}$ on May 20th.

In order to compare aircraft and in-situ data, SSS and SST measured from the RV Antea and Investigador described previously were resampled along the plane track using a nearest neighbor method in space [Fig. 2(a)] with the assumption of stable conditions within one day of the flight.

To estimate the error on the reference SSS coming from the nearest neighbor method and from the spatiotemporal variability of the SSS measurements, we extract the SSS from a high-resolution oceanic circulation numerical model, called IBI (Mercator $1 / 36^{\circ}$ ) [30] (described below), at the time and location of the RV Antea and Investigador measurements, and we resample them under the plane track using the same nearest neighbor method. These extrapolated SSS are in good agreement with the SSS modeled by IBI at the time and location of the plane track: the absolute difference is in most cases less than 0.2 pss- 78 .

Nevertheless, since the SSS is highly variable near the coast and in the Gironde plume, this resampled SSS (called 


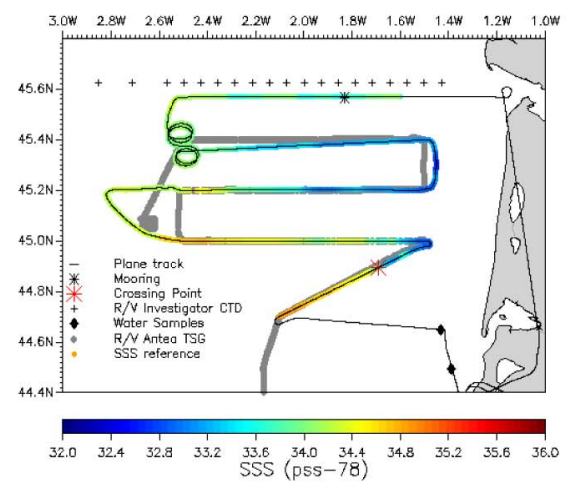

(a)

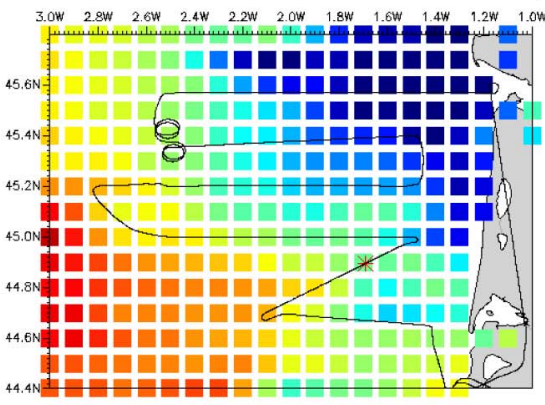

(b)

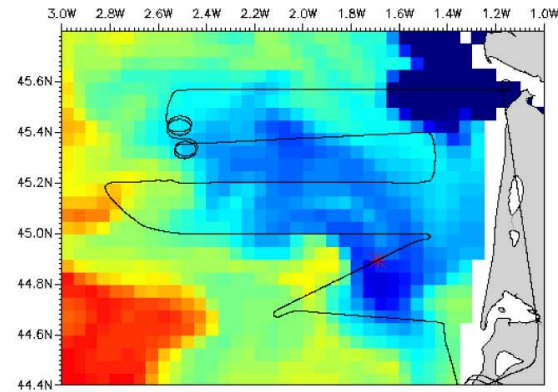

(d)

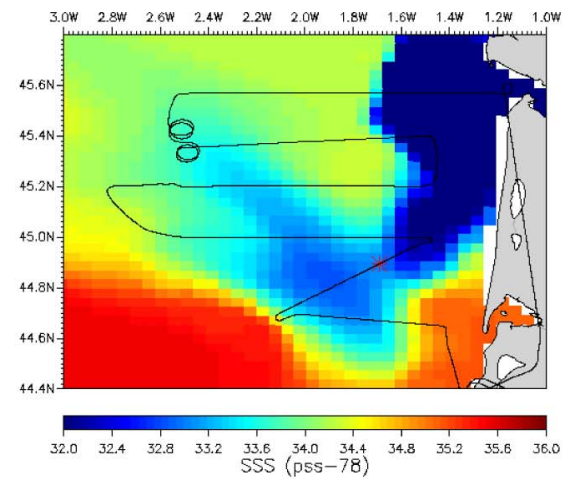

(f)

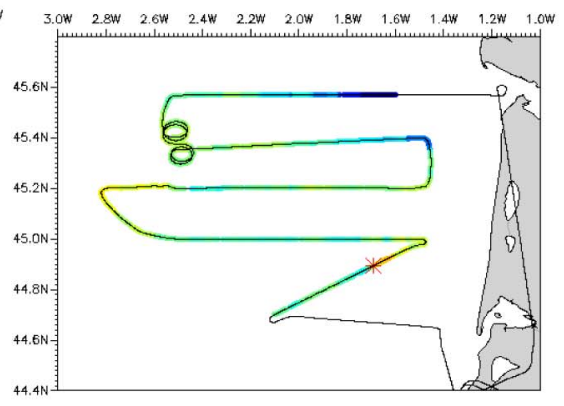

(c)

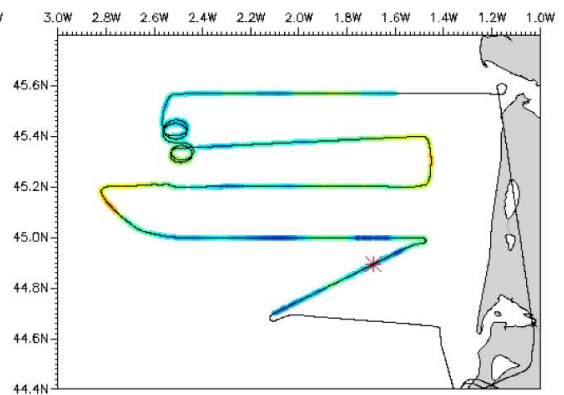

(e)

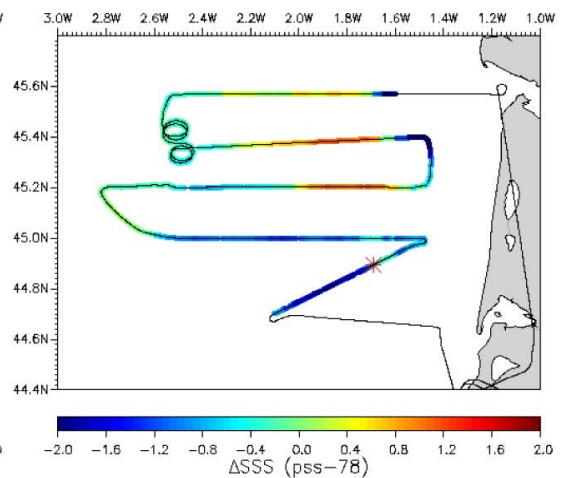

(g)

Fig. 2. Sea surface salinity corresponding to the coastal flight of May 20th, 2009, in the Gulf of Biscay. (a) Reference SSS (color line) under the plane track (black line). Locations of in-situ measurements used in the extrapolations of the reference are indicated: R/V Investigador CTD (black cross) and R/V Antea TSG (gray line). Microcat mooring (black star) and two water samples from Arcadino campaign (black diamond) used as independent validation are not used to extrapolate the reference SSS under the plane track. Crossing point between the R/V Antea and the airplane (red star); (b) SSS map from a Gauss-Markov objective analysis [29] with plane track (black line); (d) SSS map from IBI numerical model of May 20th, 2009 at 18:30 UTC [30] with the plane track (black line) and (f) SSS from Mars-3D numerical model of May 20th, 2009 at 19 UTC [31] with the plane track (black line). (c), (e), (g) SSS from (b), (d), (f), respectively, minus reference SSS. See text for details.

"reference SSS" in the following, as it will be used as reference for the aircraft remote sensing validation) is limited in the north to west of $45.6 \mathrm{~N}-1.6 \mathrm{~W}$. In the south, the end of the plane track (after $44.7 \mathrm{~N}-2.1 \mathrm{~W}$ ) was scarcely sampled, and the reference
SSS was limited to $44.68 \mathrm{~N}-2.12 \mathrm{~W}$. This SSS reference is drawn according the SSS color bar in [Fig. 2(a)].

The SST (not shown) is resampled in the same way and varies from $15^{\circ} \mathrm{C}$ to $17^{\circ} \mathrm{C}$. 


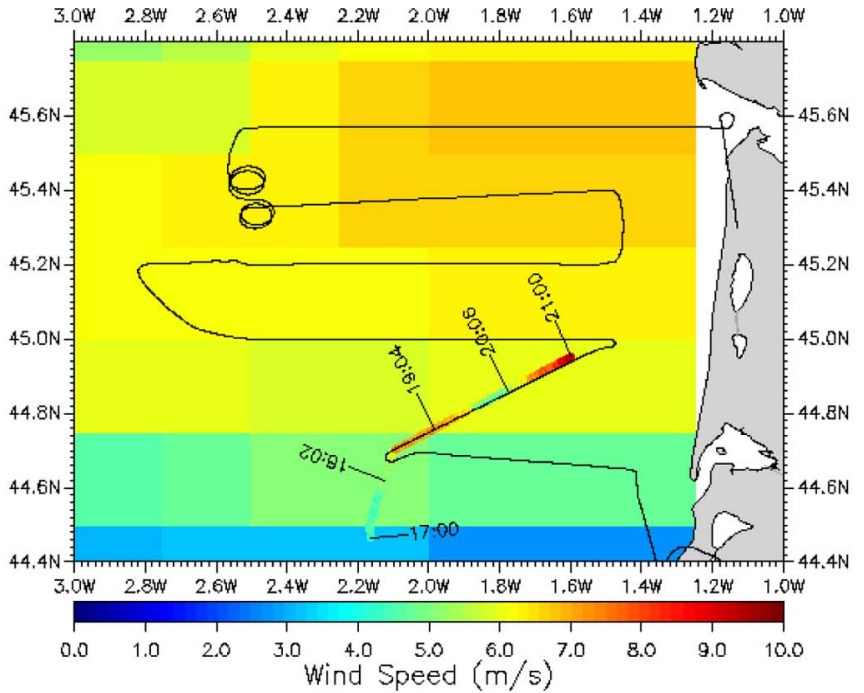

(a)

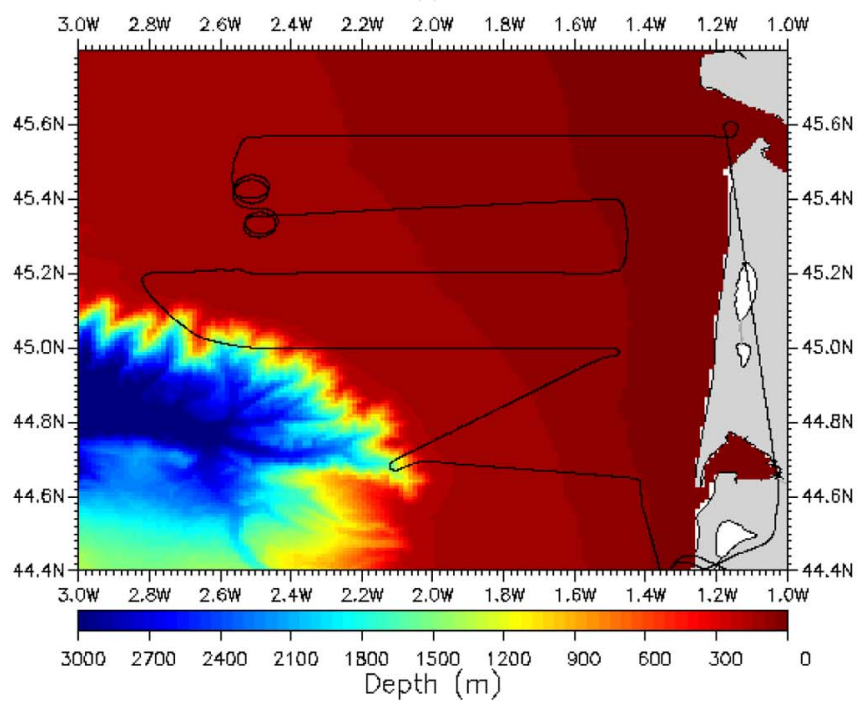

(b)

Fig. 3. (a) Field of neutral wind speed magnitude at $10 \mathrm{~m}$ height (18:36 UTC) from QuikSCAT satellite. The plane track is indicated as a black line. Wind speed measured by the RV Antea brought as neutral wind at $10 \mathrm{~m}$ height, is plotted as color line from 17:00 to 21:00 in foreground; (b) Local bathymetry with plane track (black line).

TABLE II

Biases of $T_{b}$ MeAsurements (IN K) OBSERVEd AT THE CROSSING PoInt (20:28:30; 44.89N-1.69W)

\begin{tabular}{|c|c|c|c|c|}
\hline Antenna & Polar. & $T_{b}^{\text {meas }}$ & $T_{b}^{\bmod }$ & $\overline{\Delta T_{b}}$ \\
\hline \multirow{2}{*}{ Nadir } & V & 99.47 & 99.07 & +0.39 \\
\hline & $\mathrm{H}$ & 99.55 & 99.07 & +0.49 \\
\hline \multirow{2}{*}{$30^{\circ}$} & V & 117.71 & 118.26 & -0.55 \\
\hline & $\mathrm{H}$ & 86.30 & 86.66 & -0.36 \\
\hline \multirow{2}{*}{\multicolumn{2}{|c|}{$\frac{S S S_{\text {ship }}}{33.7 \text { pss-78 }}$}} & $S S T_{\text {ship }}$ & $U_{\text {ship }}$ & \\
\hline & & $16.5^{\circ} \mathrm{C}$ & $7.3 \mathrm{~m} /$ & \\
\hline
\end{tabular}

$\mathrm{H}$ and $\mathrm{V}$ correspond to the Horizontal and Vertical polarization of the antenna frame

In addition to this "reference SSS," two additional sources of SSS data, the mooring and the two water samples, were used for analyzing CAROLS measurements.

Since the in-situ measurements used for building the reference SSS were sometimes at $20 \mathrm{~km}$ from the flight track and one day apart from the flight, we compare the "reference SSS" with three SSS fields covering the whole region: a map derived with a classical Gauss-Markov objective analysis (OA) applied to in-situ data as defined in [29] and outputs of two high-resolution numerical oceanic circulation models, less than $0.5 \mathrm{~h}$ apart from the flight time. These comparisons are intended to identify parts of the flight where the SSS is highly variable.

The map derived with the OA [Fig. 2(b)] is centered on the flight period (20 May); it uses a climatology as first guess and all in-situ measurements available in this region from 11 to 31 May [29]. At first order, it is in good agreement with the reference SSS [Fig. 2(c)]. However, the westward extension from the coast of the Gironde plume is less evident in the reference SSS and in the RV Investigador observations than in the result of the OA, which refers to a period of 20 days. This lesser extent of the Gironde plume is also confirmed by the mooring SSS (not shown, equal to 33.58 pss-78 at 19UTC). On the east part of 1.8W-45.4N (about 19:37-19:47 flight time), we get again a lower salinity (up to 0.8 pss-78) compared to the reference SSS due to a larger extent of the Gironde plume from the 20 days interpolation.

The numerical model results used in the following analysis come from on one hand by the IBI (Mercator $1 / 36^{\circ}$ ) model with climatological river run-offs [30], and on the other hand by the Mars-3D model with daily observed river run-offs [31].

Fig. 2(d) represents the hourly average SSS field of May 20th at 18:30 UTC from IBI with the plane track in foreground and Fig. 2(e) the difference with respect to reference SSS. There is a good agreement with the reference SSS for the first part of the flight track (track $45.6 \mathrm{~N}, 45.4 \mathrm{~N}$ and $45.2 \mathrm{~N}$ ), but on the track $45.0 \mathrm{~N}$ and south of it, SSS from the model is lower than the reference SSS. The high SSS pattern extends further west in the measurements compared to the IBI model outputs.

Fig. 2(f) represents the hourly average SSS field of May 20th at 19 UTC from Mars 3-D with the plane track in foreground and Fig. 2(g) the difference with respect to reference SSS. There is a good agreement at $45.6 \mathrm{~N}$, but at $45.4 \mathrm{~N}$ and $45.2 \mathrm{~N}$ a saltier tongue coming from the north creates large east-west gradients not seen on the measurements nor in IBI SSS (about +1 pss-78 and -2 pss-78). The westem part of the plane track presents a good agreement between Mars 3-D and reference SSS, but on the track $45.0 \mathrm{~N}$ and south of it, the modeled SSS is about 1 pss-78 lower than the reference.

Wind speed was recorded in this area both by the QuikSCAT satellite at $18 \mathrm{~h} 36$ UTC and along the plane track by the RV Antea [Fig. 3(a)]. Wind speed derived from QuikSCAT indicates wind speed between 5 and $7 \mathrm{~m} / \mathrm{s}$ along the flight track [plotted in background in Fig. 3(a)]. Unfortunately, when QuikSCAT flew over the RV Antea, the ship measured a wind speed varying from $5 \mathrm{~m} / \mathrm{s}$ at $18: 00$ to $7.5 \mathrm{~m} / \mathrm{s}$ at 19:00 so that it is difficult to compare punctual ship measurements with QuikSCAT wind speed integrated over $25 \times 25 \mathrm{~km}^{2}(5 \mathrm{~m} / \mathrm{s}$ in the pixel crossing the ship track at 18:36).

Due to long time interval needed by the RV Antea to sample wind speed over the flight track, we chose to use QuikSCAT as wind speed reference in spite of the time difference of about $2 \mathrm{~h}$ between CAROLS and QuikSCAT data. When the plane flew over the RV Antea $(20: 28,44.89 \mathrm{~N}, 1.69 \mathrm{~W})$ a strong 
This article has been accepted for inclusion in a future issue of this journal. Content is final as presented, with the exception of pagination.

TABLE III

Contributions in $T_{b}(\mathrm{~K})$ OF Model Components Along the Flight TRaCK Where ReFerence SSS Has BEEN DeRIVED

\begin{tabular}{l|cc|cc|cc}
\hline & \multicolumn{2}{|c|}{ Nadir } & \multicolumn{4}{c|}{$30^{\circ}$} \\
\hline & \multicolumn{2}{|c|}{$\mathrm{H}$ or $\mathrm{V}$} & \multicolumn{2}{c|}{$\mathrm{V}$} & \multicolumn{2}{c}{$\mathrm{H}$} \\
\hline & $\mu$ & $\sigma$ & $\mu$ & $\sigma$ & $\mu$ & $\sigma$ \\
\hline total & 98.75 & 0.35 & 118.27 & 0.55 & 86.15 & 0.42 \\
flat & 92.96 & 0.27 & 113.03 & 0.54 & 78.46 & 0.36 \\
tscale & 1.74 & 0.12 & 1.08 & 0.10 & 2.73 & 0.10 \\
atm & 1.77 & 0.01 & 2.03 & 0.01 & 2.42 & 0.02 \\
scatgal & 2.27 & 0.01 & 2.12 & 0.06 & 2.54 & 0.08 \\
\hline
\end{tabular}

total: sum of all the contributions, flat: flat surface, tscale: roughness contribution according to a two-scale model, atm: atmospheric contribution, scatgal: sky signal scattered by the sea surface. For details refer to the text.

variation both in wind speed (5 to $10 \mathrm{~m} / \mathrm{s}$ ) [Fig. 3(a)] and in SSS [Fig. 2(a)] was measured by the RV Antea. In the following, unless specified, wind estimates under the flight track are those derived from QuikSCAT.

Concerning water depth, it has to be noted that the plane track remains over the continental shelf in the Gulf of Biscay [Fig. 3(b)] [32], but is near the shelf border between 20:08 to $20: 12$ and $20: 33$ to $20: 37$.

\section{METHODS}

\section{A. Brightness Temperature Simulations and Inversion Methods}

In a first step, the measured $T_{b}$ referenced in the antenna frame are compared with simulated $T_{b}$ obtained with a direct model. We used the Terrestrial Radiometry Analysis Package developed at IFREMER [33], [34], in a configuration that takes into account the CAROLS antenna lobes geometry, the aircraft attitude, and the physical models implemented in the SMOS data processing of the ocean salinity. The different contributions to emissivity are estimated as follows:

- the atmospheric emissivity and absorption from [35];

- the sea surface emissivity for a flat surface from [36];

- the roughness contribution to the sea surface emissivity according to a two-scale model using the Durden and Vesecky $\times 2$ wave spectrum [37];

- the scattering of the sky radiation by the sea surface according to [38].

Geophysical parameters needed to take into account these contributions are as follows: Atmospheric pressure and relative humidity are taken from the European Center for Medium range Weather Forecast; SSS and SST are from the "reference" values as explained in the previous section; Wind speed was derived from QuikSCAT measurements recorded at 18:36 UTC (up to $2 \mathrm{~h}$ before the last CAROLS measurement over the ocean).

All these contributions are projected in the polarization reference frame of the antennas so that measurements of the two antenna ports can be directly compared with simulations.

The contributions (as described above) to the brightness temperature modeled for each antenna are summarized in (Table III). Mean and standard deviation of each antenna and polarization are computed on $T_{b}$ at the flight track where reference SSS has been derived. The main contribution comes from the flat sea model (highly related to the SSS), which dominates in the $T_{b}$ variations. At the second order, the $T_{b}$ variations are explained by the contribution due to the roughness (tscale), as well as by the sky scattering (scatgal) for the $30^{\circ}$ antenna. The contribution of the atmosphere is mainly constant as the altitude and the incidence angle are constant.

For the data corresponding to the time of the ship/plane crossing, we compared $T_{b}$ measurements and direct simulations obtained using in-situ parameters measured by the ship (SSS, SST, and wind speed). We used this comparison to remove biases between measured and modeled $T_{b}$, without any asumption on the origin of the biases originating from the model or from the data. Results are summarized in (Table II). At nadir, biases (measured with respect to simulated $T_{b}$ ) are positive and range from $0.39 \mathrm{~K}$ to $0.49 \mathrm{~K}$ for the $\mathrm{V}$ and $\mathrm{H}$ polarizations, respectively. For the $30^{\circ}$ incidence angle antenna, biases are negative and range from $-0.36 \mathrm{~K}$ to $-0.55 \mathrm{~K}$ for the $\mathrm{H}$ and $\mathrm{V}$ polarizations, respectively. In the rest of our analysis, unless otherwise specified, these biases were removed from the data.

Comparisons between measured and simulated $T_{b}$ are discussed in Section IV. In the following section, we will present different methods to retrieve the salinity from $T_{b}$ measurements.

\section{B. Sea Surface Salinity Retrieval}

Using the models presented above, observations of $T_{b}$ have been inverted using two different methods. The first one, called single parameter retrieval, uses only the SSS sensitivity of $T_{b}$ assuming that the wind speed is well known. The second one, called multiparameter retrieval, is used to retrieve both wind speed and SSS, requiring some a priori knowledge on wind speed. In both cases SST is from the reference SST, which is between $15^{\circ} \mathrm{C}$ and $17^{\circ} \mathrm{C}$ along the flight track.

1) Single Parameter Retrieval: SSS is retrieved for each polarization on each antenna data product, using the sensitivity of $T_{b}$ to SSS, assuming that wind speed is perfectly known. First, we calculate the difference between the measured and simulated $T_{b}$ with a prescribed value of SSS of 34 pss-78 and other geophysics conditions taken as explained in Section II-B. Then this difference in $T_{b}$ is related to the SSS shift [with respect to the 34 pss-78 value using a linear model as in (1)]. Errors due to the $T_{b}$ versus SSS sensitivity linearization are below $2.5 \%$ in the range of 32 to 36 pss- 78 .

$$
\begin{aligned}
\Delta T_{b} & =T_{b \text { meas }}-T_{b} \text { model }\left(U_{Q S C A T}, S S T_{\text {ship }}, S S S=34\right) \\
S S S & =34+\frac{d S S S}{d T_{b}} \cdot \Delta T_{b}
\end{aligned}
$$

where $d S S S / d T_{b}$ (inverse of SSS sensitivity; see Table I) was estimated at $S S T=15.6{ }^{\circ} \mathrm{C}$ and $S S S=34$ pss -78 which correspond to the median values of these parameters along the flight track.

This method was applied on each polarization and each antenna. Hence, four SSS are retrieved. In the following, we call "Retrieval 1" the SSS retrieved using the V-polarization of the $30^{\circ}$ antenna that corresponds to the most sensitive configuration to SSS (see Table I) and "Retrieval 2" the SSS retrieved using each polarization on each antenna.

2) Multiparameter Retrieval: In this method, SSS and wind speed are retrieved simultaneously using the iterative 
TABLE IV

COMParison of SSS RETRIEVEd From Radiometric MEASUREMENTS to REFERENCE SSS (1530 MEASUREMENTS)

\begin{tabular}{|c|c|c|c|c|c|c|c|}
\hline Number & Type of retrieval & $\begin{array}{l}T_{b} \text { biases } \\
\text { correction }\end{array}$ & $\begin{array}{l}\text { a priori } T_{b} \\
\text { Noise }(K)\end{array}$ & $\begin{array}{l}\text { Biases } \triangle S S S \\
\text { (pss-78) }\end{array}$ & $\begin{array}{l}\text { std( }(\Delta S S S) \\
(\mathrm{pss}-78)\end{array}$ & $\begin{array}{l}\operatorname{rms}(\Delta S S S) \\
(\mathrm{pss}-78)\end{array}$ & Correlation \\
\hline 1 & Single parameter - Tv30 & Yes & - & -0.15 & 0.33 & 0.36 & 0.88 \\
\hline 2 & Single parameter & Yes & - & -0.23 & 0.33 & 0.40 & 0.86 \\
\hline 3 & Multi parameter - Slant & Yes & 0.15 & -0.15 & 0.44 & 0.46 & 0.83 \\
\hline 4 & Multi parameter & Yes & 0.15 & -0.20 & 0.41 & 0.45 & 0.83 \\
\hline 5 & Multi parameter & No & 1 & -0.15 & 0.30 & 0.33 & 0.90 \\
\hline
\end{tabular}

Levenberg and Marquard method [39]-[42]. Using a maximum-likehood Bayesian approach, assuming a Gaussian distribution of the errors on $T_{b}$, SSS and wind speed are iteratively estimated. The retrieval method starts with an a priori value on SSS and WS that influence the $T_{b}$ and with set values on the uncertainties $\sigma_{P_{j}}$. The method minimizes the following cost function:

$$
\begin{aligned}
\chi^{2}= & \sum_{i} \frac{\left(T_{b i}^{\text {meas }}-T_{b i}^{\text {mod }}(S S S, W S)\right)^{2}}{\sigma_{T_{b i}^{\text {mod }}}^{2}+\sigma_{T_{b i}}^{2}} \\
& +\frac{\left(S S S^{\text {retrieved }}-S S S^{\text {prior }}\right)^{2}}{\sigma_{S S S}^{2}} \\
& +\frac{\left(W S^{\text {retrieved }}-W S^{\text {prior }}\right)^{2}}{\sigma_{W S}^{2}}
\end{aligned}
$$

where $T_{b i}$ correspond to (Nadir-V; Nadir- $\mathrm{H} ; 30^{\circ}-\mathrm{V} ; 30^{\circ}-$ $\mathrm{H})$ measurements or models. Prior value of these parameters was chosen as: $S S S^{\text {prior }}=34 \mathrm{pss}-78, \sigma_{S S S}=20 \mathrm{pss}-78$, $W S^{\text {prior }}=6.5 \mathrm{~m} / \mathrm{s}$, and $\sigma_{W S}=2 \mathrm{~m} / \mathrm{s}$. We decided to put a high value on the SSS uncertainty (20 pss-78) to give a little weight to the SSS constraining term. If we choose instead a prior value of 35 pss- 78 or a prior standard deviation of 100 pss78 , final statistics remain the same. The wind speed uncertainty is deduced from the R/V Antea measurements. We arbitrarily put an error on the simulated $T_{b}$ of $\left(\sigma_{T_{b i} \bmod }=0.1 \mathrm{~K}\right)$, and we chose two types of $T_{b}$ noise on the measurements, either consistent with the radiometric accuracy $(0.1 \mathrm{~K})$ for "Retrievals 3 and 4," or consistent with the order of magnitude of biases $(1 \mathrm{~K})$ for "Retrieval 5." In this last case, $T_{b}$ measurements are not corrected for biases before retrieval. In the case of "Retrievals 5 and 4," the two antennas and polarizations are used whereas for "Retrieval 3" only the two polarizations of the $30^{\circ}$ antenna are used. Unlike the single parameter retrieval, an exact knowledge of the wind speed is not necessary. An a priori estimation of its value together with the standard deviation of its error is sufficient.

The first four columns of Table IV summarize the conditions of inversion for the five retrieval cases.

\section{RESUlTS}

\section{A. Measured and Simulated Brightness Temperatures}

We limit our analysis in this section to the flight period during which our reference SSS is available.

Fig. 4 presents results of the direct simulation with respect to the measured brightness temperature, for each polarization and antenna. Statistics of these comparisons are reported in
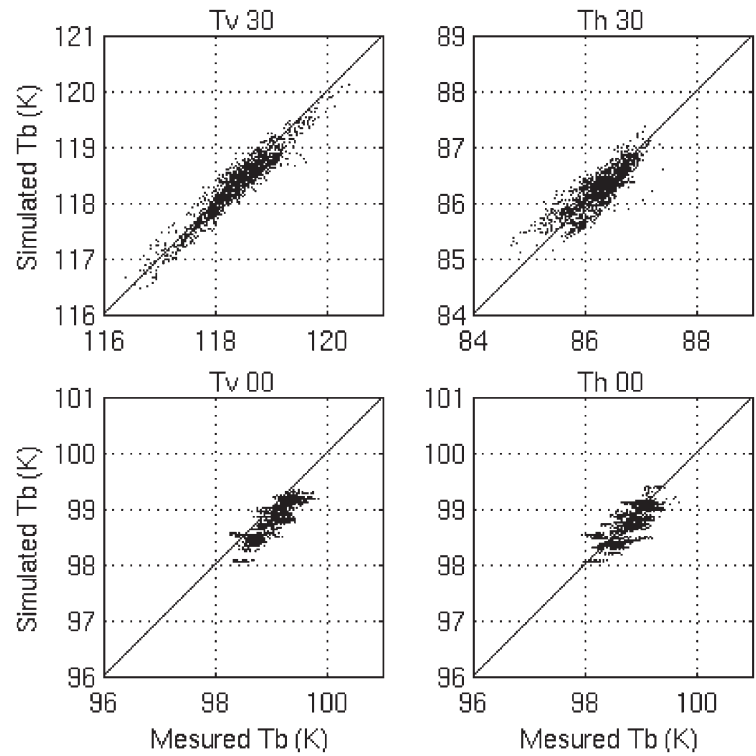

Fig. 4. Radiometric measurements versus simulated brightness temperature. Each subplot represents one of the two antenna and polarization. (a), (b) for the $30^{\circ}$ antenna, respectively the $\mathrm{V}$ and $\mathrm{H}$ polarization, whereas (c) and (d) for the nadir antenna, respectively, the $\mathrm{V}$ and $\mathrm{H}$ polarization.

TABLE V

RADIOMETRIC MEASUREMENTS VERSUS SiMULATED BRIGHTNESS TEMPERATURE (1530 MEASUREMENTS)

\begin{tabular}{c|c|c|c|c}
\hline Ant. & Polar. & Bias $\Delta T_{b}(\mathrm{~K})$ & $\operatorname{rms}\left(\Delta T_{b}\right)(\mathrm{K})$ & Correlation \\
\hline Nadir & $\mathrm{V}$ & +0.25 & 0.30 & 0.86 \\
Nadir & $\mathrm{H}$ & +0.07 & 0.21 & 0.80 \\
\hline $30^{\circ}$ & $\mathrm{V}$ & +0.08 & 0.18 & 0.96 \\
$30^{\circ}$ & $\mathrm{H}$ & +0.04 & 0.22 & 0.84 \\
\hline \multicolumn{4}{|c}{$\Delta T_{b}=T_{b}^{\text {mes }}-T_{b}^{\text {mod }}$}
\end{tabular}

(Table V). We notice that the excursion of the $30^{\circ}$ antenna measurements is more important than that of the nadir antenna. This is because the sensitivity to incidence angle variations is larger at $30^{\circ}$ than at nadir (Table I) particularly in V-polarization. In addition to this influence, the dynamics of $T_{b}$ at $30^{\circ}$ and V-polarization is larger because of the larger sensitivity to the SSS (Table I). In H-polarization at $30^{\circ}$ incidence angle, data are noisier, probably due to a higher wind speed sensitivity, and to a wind speed accuracy not better than $2 \mathrm{~m} / \mathrm{s}$ in this nonhomogeneous and nonstationary situation.

According to Table V, after correcting the measurements for biases observed at the ship/plane crossing, on average over the flight period considered here, small biases remain with an order of magnitude smaller than those at crossing point except for V-polarization on nadir antenna. 


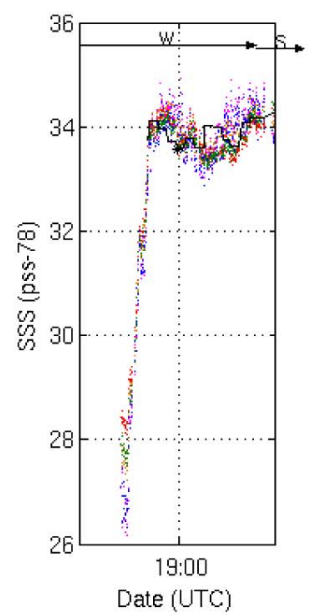

(a)

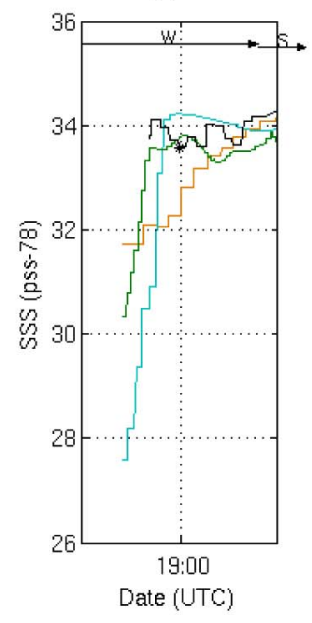

(c)

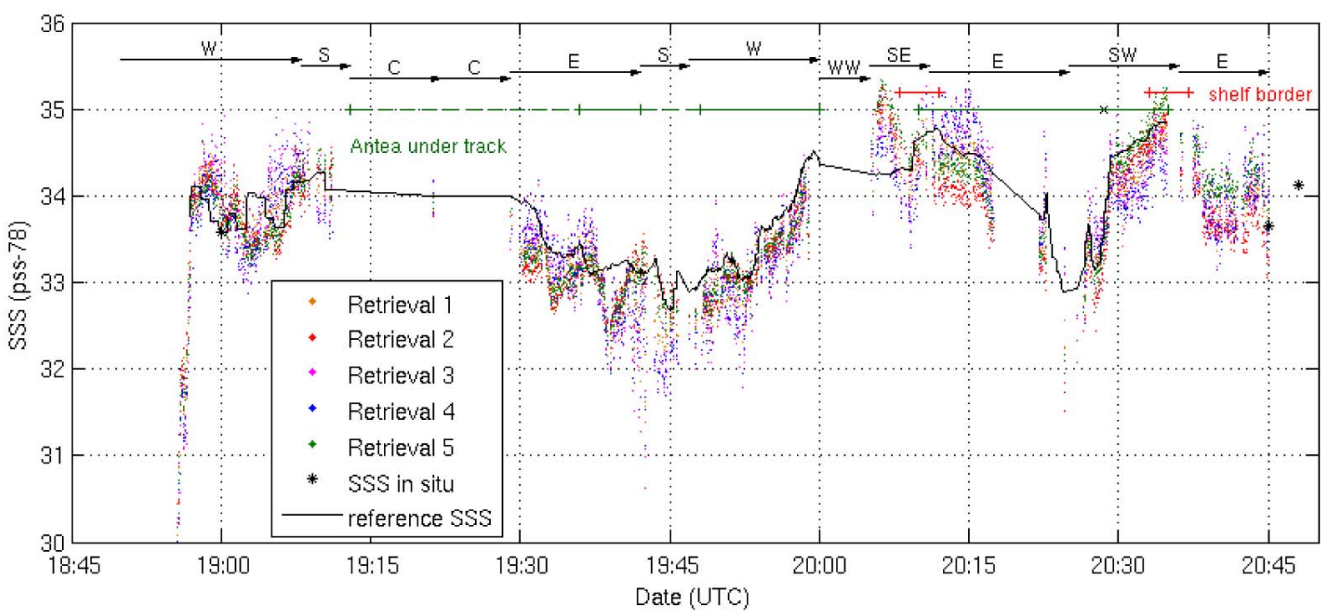

(b)

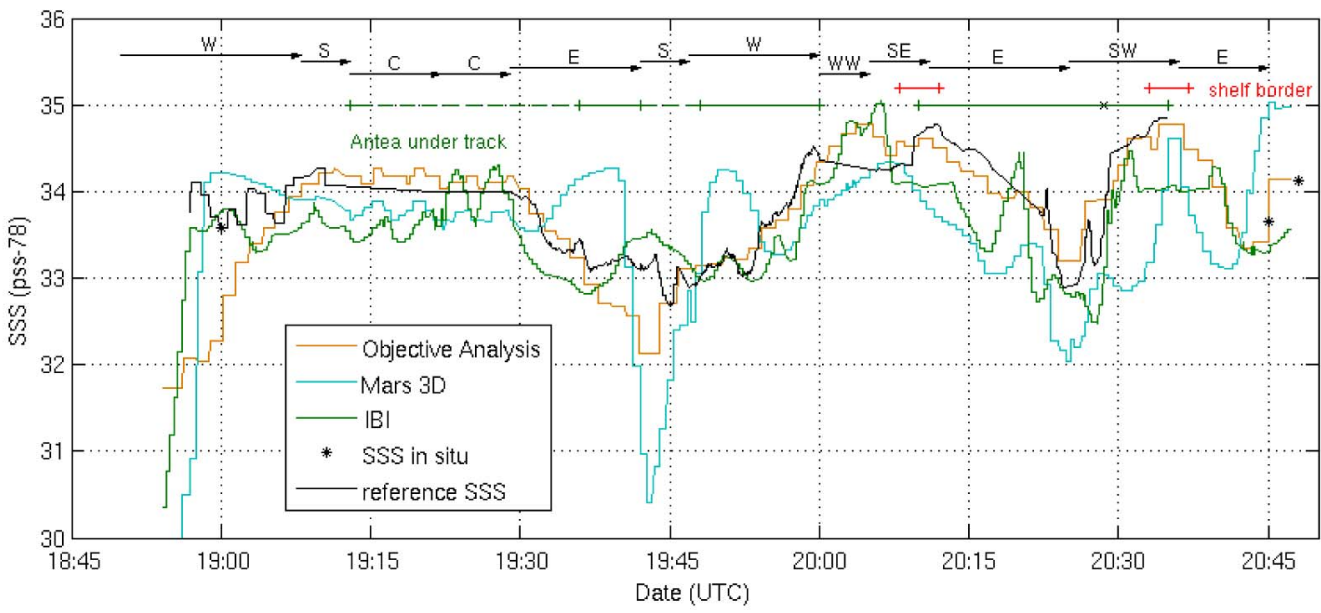

(d)

Fig. 5. SSS as a function of the flight time along the plane track. (b) represents the retrieved SSS using the different algorithms whereas (d) represents the different SSS resampled under the flight track from SSS map shown in [Fig. 2]. (a) and (c) represent the flight beginning in the Gironde plume with an expanded salinity scale. In the top of the figures, W, S, E represent the true heading as cardinal points; C and WW point out, respectively, periods of Circle flights and Wing-wags movements. Reference SSS is plotted as a black line in the two figures. Samples from the Arcadino campaign and the microcat mooring are represented with a black star. In the middle of the figure, red line represents the period during which the plane was on the border of the shelf, the green line represents the locations where the RV Antea was on the plane track and in the neighborhood for the dashed line. The black cross on the green line points out the time when the plane track crossed the ship (20h28, $44.89 \mathrm{~N}, 1.69 \mathrm{~W})$.

\section{B. Retrieved Sea Surface Salinity Versus Reference SSS}

Fig. 5(b) shows the five retrieved SSS, described in Section III-B, as a function of time along the flight. These values are compared to the reference SSS (see Section II-B). All the statistics are reported in (Table IV). The five retrievals of SSS have similar variability along the plane track. The maximum differences between the five estimates at a same location is less than 0.55 pss- 78 for $70 \%$ of the data.

Once the SSS fields from Mars-3D, IBI and OA SSS fields are resampled under the plane track (using a nearest temporal neighbor method for numerical models), we observe differences of few pss-78 with reference SSS or SSS derived from radiometric measurements [Fig. 5(d)].

On the first part of the flight, up to 18:58 in the Gironde plume, all retrievals indicate a very strong gradient of salinity starting with very fresh salinities, as low as 27 pss-78 [Fig. 5(a) and (c)]. Unfortunately, no in-situ measurements were available there. These low values are in agreement with the Mars-3D
SSS, but the westward extension of the low salinity plume is in slightly better agreement with IBI model. The westward extension of the low salinity plume is overestimated by the OA as the latter averages the SSS over 20 days.

Between 18:58 and 19:11, the five retrievals agree with the reference SSS and the microcat mooring SSS. Between 19:30 and 19:59, the plane flies eastward along $45.4 \mathrm{~N}$, southward along 1.45W (close the shore) and westward along 45.2N. Reference SSS, IBI, OA, and radiometric measurements see a decrease of SSS when approaching the coast. Nevertheless, when the plane flies southward, radiometric measurements are in better agreement with $\mathrm{OA}$ which is about 0.8 pss-78 lower than reference SSS. Indeed the RV Antea was sailing $20 \mathrm{~km}$ west of the flight track off the coast. During this period, Mars 3-D simulation behaves differently from other SSS: on the tracks $45.4 \mathrm{~N}$ and $45.2 \mathrm{~N}$, Mars 3-D simulates a SSS tongue of about 34 pss-78 coming from the northwest [see Fig. 2(f) and (g) and description] not seen on other fields and near the coast, and a 


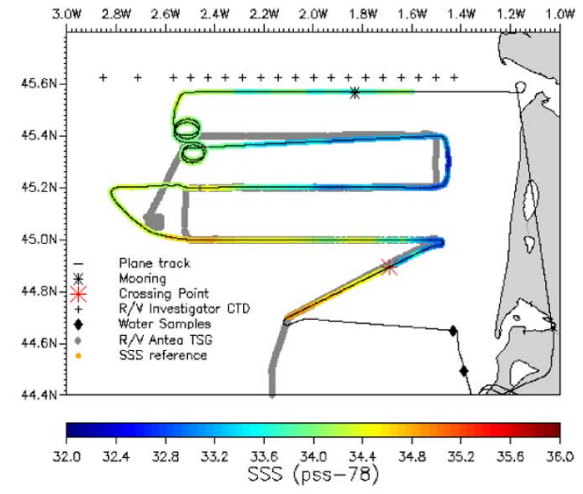

(a)

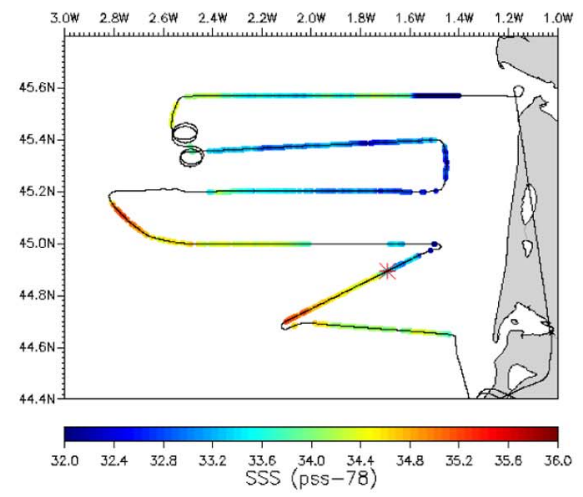

(b)

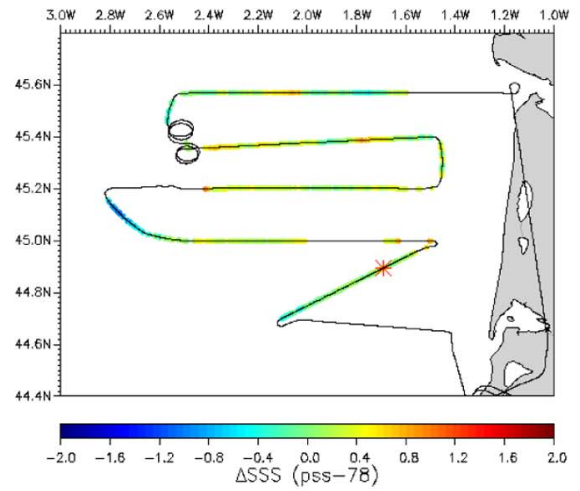

(c)

Fig. 6. (a) SSS reference, (b) Retrieved SSS from CAROLS radiometric measurements using the retrieval method 5, (c) retrieved SSS minus reference SSS where SSS reference is available.

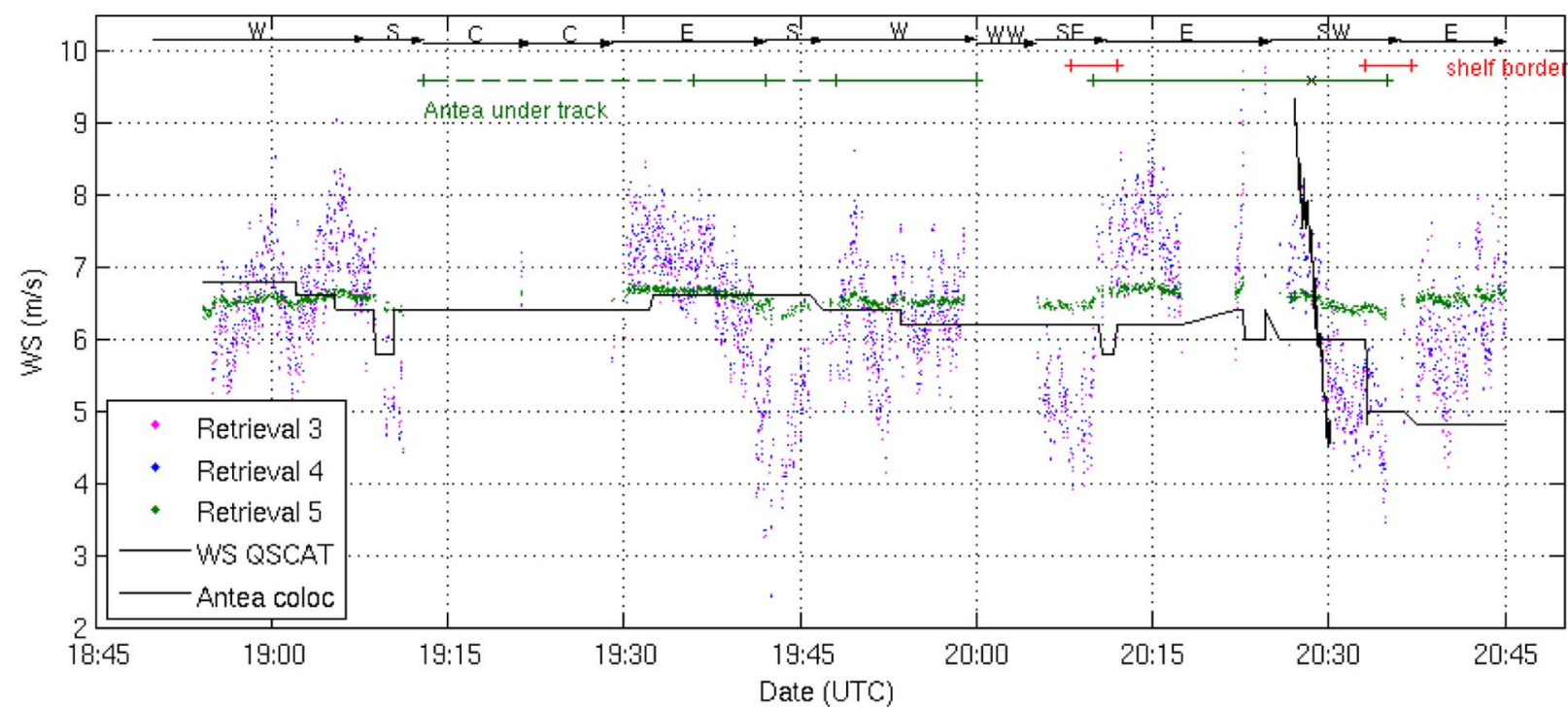

Fig. 7. Wind speed as a function of the flight time along the plane track. Color dots represent the wind speed estimation using the multiparameter retrieval. Wind speed measured by the QuikSCAT scatterometer at $18 \mathrm{~h} 36$ for all the plane track is represented as a black line (input for single parameter retrieval). The black line between $20: 27$ at $9.3 \mathrm{~m} / \mathrm{s}$ and 20:30 at $4.5 \mathrm{~m} / \mathrm{s}$ represents the spatial interpolation of the RV Antea wind speed measurements. Other legends in this figure are the same as those used for Fig. 5.

large freshening with SSS fresher by up to 2 pss-78 than other estimates.

Between 20:10 and 20:12, with the plane flying toward south-east close to the continental shelf border, the retrieved SSS does not fit well with the reference SSS (there was one day lag between in-situ SSS and the flight), but instead agrees with IBI SSS that indicates a penetration of a salty waters coming from the west. Between 20:12 and 20:16, the plane flies eastward along $45 \mathrm{~N}$ up to longitude $2.0 \mathrm{~W}$. There, the five retrieved SSS mismatch. Retrievals 3 and 4 overestimate the SSS according to the reference SSS by about 0.3 pss-78. Retrievals 5 and 2, underestimate the SSS by about, respectively, 0.2 and 0.5 pss-78, whereas Retrieval 1 agrees with the reference SSS and the OA. SSS from oceanic models are fresher by about 1 pss-78 than reference SSS and are fresher than the lowest retrieved SSS (Retrieval 2).

In the following period, up to 20:36, the five retrieved SSS are in the range of the measured and simulated SSS, but
SSS retrieved with retrieval 5 agrees better with the reference SSS that was derived from in-situ measurements close in time and space.

For the last part of the flight (after 20:36), reference SSS is not available, but the five retrieved SSS are in the range of the high-resolution numerical models outputs, the OA and one of the two water samples from Arcadino campaign [Fig. 5(d)].

Table IV shows results of the five retrievals: SSS is retrieved with a scatter to the reference SSS of less than 0.4 pss-78, and with a correlation better than 0.8 ; the $95 \%$ confidence interval is 0.02 pss-78. There remain biases of about -0.2 pss-78 regardless the method, antenna, or polarization used.

When comparing the five retrieved SSS with the reference SSS, the lowest biases and the best correlation of retrieved SSS are observed for Retrievals 1 and 5 (Table V). These two retrievals represent two opposite approaches: Retrieval 1 neglects errors on $T_{b}$ and wind speed and uses only the most sensitive configuration to SSS (V-polarization at $30^{\circ}$ ), whereas 
TABLE VI COMPARISON OF THE SSS RETRIEVED FROM CAROLS (RUN R5) With REFERENCE, OBJECTIVE ANALYSIS, AND MODELS (IBI AND MARS 3-D)—1530 MEASUREMENTS

\begin{tabular}{l|c|c|c|c}
\hline & $\begin{array}{l}\text { Biases } \Delta S S S \\
(\mathrm{pss}-78)\end{array}$ & $\begin{array}{l}\mathrm{std}(\Delta S S S) \\
(\mathrm{pss}-78)\end{array}$ & $\begin{array}{l}\operatorname{rms}(\Delta S S S) \\
(\mathrm{pss}-78)\end{array}$ & Correlation \\
\hline CAROLS (R5) - Reference & -0.15 & 0.30 & 0.33 & 0.90 \\
\hline CAROLS (R5) - OA & 0.09 & 0.61 & 0.62 & 0.62 \\
CAROLS (R5) - IBI & 0.20 & 0.49 & 0.53 & 0.70 \\
CAROLS (R5) - Mars 3D & 0.11 & 0.93 & 0.94 & 0.18 \\
\hline Reference - OA & 0.24 & 0.49 & 0.54 & 0.74 \\
Reference - IBI & 0.35 & 0.38 & 0.52 & 0.73 \\
Reference - Mars 3D & 0.26 & 0.92 & 0.96 & 0.04 \\
\hline
\end{tabular}

Retrieval 5 allows large adjustment of $T_{b}$ measured in $\mathrm{V}$ and $\mathrm{H}$-polarization at nadir and $30^{\circ}$ and adjustment of wind speed.

Fig. 6(a) [identical to Fig. 2(a)] represents the reference SSS. Fig. 6(b) represents the best radiometric retrieved SSS (Retrieval 5) and Fig. 6(c) the difference with respect to reference SSS. There is a very good agreement with the reference SSS on the main part of the track, except around $45.1 \mathrm{~N}$ $2.1 \mathrm{~W}$, where no in-situ measurements have been performed. Moreover, this area, as well as $44.7 \mathrm{~N}-2.1 \mathrm{~W}$, are near the shelf border [Fig. 3(b)], where the sea surface conditions are highly variable.

One advantage of multiparametric retrievals is that they have the capability of adjusting the wind speed to the local variability under the plane track. The retrieved wind speeds are displayed on Fig. 7. With Retrieval 5, the large noise imposed on $T_{b}$ prevents a large deviation of retrieved wind speed with respect to the prior value $(6.5 \mathrm{~m} / \mathrm{s})$. On the other hand, when a low noise is imposed on $T_{b}$ (retrievals 3 and 4), the retrieved wind speed is much noisier and exhibits variations of $2 \mathrm{~ms}^{-1}$ with respect to QuikSCAT wind speed. However, near the crossing of the plane and ship, the ship measurements are characterized by a large variation in wind speed. Assuming that this variation in time reflects spatial variation along the ship cruise, we colocated in space the wind speed recorded on the ship between 19:58 and 20:58 (around the crossing point at 20:28). This spatial colocation corresponds on Fig. 7 to flight time between 20:27:03 and 20:30:05 (80 samples). It is remarkable that the retrieved wind speed (Retrievals 3 and 4) during this period is in better agreement with the ship colocated measurements than the QuikSCAT wind speeds; average of the difference between retrieved and colocated ship wind speed is of $0.1 \mathrm{~m} / \mathrm{s}$ with a standard deviation of the difference of $0.9 \mathrm{~m} / \mathrm{s}$ for the retrievals 3 and 4 whereas bias and standard deviation of the difference are, respectively, 0.8 and $1.3 \mathrm{~m} / \mathrm{s}$ for comparison between colocated measurements and QuikSCAT.

During this period of highly variable wind speed, the retrieved SSS is closer to reference when using a multiparametric retrieval than when using a single parameter retrieval: biases are of -0.04 pss- 78 and 0.07 pss-78 for retrievals 3 and 4 , whereas retrievals 1,2 , and 5 are, respectively, of 0.10 pss-78, 0.37 pss-78, and 0.14 pss-78.

We further tested the possible effect of the spatial variability of the wind speed at a resolution lower than $25 \mathrm{~km}$ using the high-resolution QuikSCAT wind speed from [43] $(2.5 \mathrm{~km}$ resolution). No improvement on the whole flight statistic is observed, possibly because of the temporal variation of the wind since the satellite passed at 18:36.
If instead of comparing the retrieved SSS with reference SSS, we compare them with the objective analyzed SSS or the oceanic models SSS, correlations are worse, and biases are opposite (positive-Table VI for retrieval 5). Correlation and std of the difference are better for IBI model than the OA or Mars 3-D model (Table VI, lines 1-4). Furthermore, retrieved SSS (Retrieval 5-R5) is better than SSS fields derived from coastal numerical model or OA [Table VI, lines 1 and 5-7; and Fig. 6(c) versus Fig. 2(c), (e) and (g)].

Hence, although our reference SSS was derived with measurements taken sometimes at plus or minus one day and $20 \mathrm{~km}$ from the flight, it is closer to radiometer SSS than regional SSS fields; this demonstrates the importance of conducting in-situ measurements close in space and time with the flight campaign, particularly in coastal zone where SSS is highly variable.

\section{Discussion AND CONCLUSION}

In this paper, we showed that we are able to retrieve values of SSS from airborne L-band radiometric measurements consistent with ground truth (standard deviation of the error of 0.3 pss-78 with SSS varying between 32.5 and 35 pss-78). This standard deviation of the error is about a factor 2 larger than the one expected from the radiometric measurement error $(0.06$ to $0.08 \mathrm{~K}$ is equivalent to about 0.15 pss-78, see Section II-A) alone. A similar discrepancy is observed when comparing SMOS and in-situ salinities [44]. The error on retrieved salinities, as derived from comparisons with ARGO data, is on the order of 0.4 pss-78, larger by a factor 2 to 4 than those expected, whereas the rms error on SMOS $T_{b}$, after removing systematic biases in the field of view, is consistent with expectations [45]. This suggests that part of the L-band signal is not fully described by present models and auxiliary parameters.

We also show that a ship survey dedicated to SSS measurements under the flight track and SSS fields derived from numerical models or OA greatly contributes to interpret the radiometer measurements. It is remarkable that although there is some scatter on our retrieved SSS depending on the polarizations and antennas used in the retrieval, this uncertainty is smaller than the difference between the various SSS estimates derived in this area from high-resolution models or OA of insitu data [Fig. 5(d)].

We discarded several RFIs in horizontal polarization in the second part of the flight on both antennas, and we cannot exclude that some weak RFIs remain in horizontal polarization resulting in errors in our retrievals. The SSS retrieved between 20:12 and 20:16, during which the various retrievals give 
different systematic biases, support this hypothesis since the retrieval using the $30^{\circ}$ antenna and the V-polarization seems unaffected.

One source of uncertainty is probably due to the way roughness effects are taken into account. First, wind speed measurements are not available at the same time of the flight or at the spatial resolution of the radiometer data. Second, in such a coastal area, wind speed is probably not enough to characterize the roughness due to fetch effects.

Nevertheless, our study shows that inversion of CAROLS data using SMOS direct models and retrieval methods performs rather well in terms of retrieved SSS in such a complicated situation. We find also that the SSS retrieved from the vertical polarized $T_{b}$ is of better quality than the one retrieved from both polarizations; this could be explained by our imperfect modeling of the sea surface roughness effects, since the vertical polarization is more sensitive to SSS and less sensitive to the roughness than the horizontal polarization. More surprising is the fact that, with a reasonable noise on $T_{b}$, a multiparametric retrieval applied after biases correction, does not perform better than a single parameter inversion based on an prescribed wind speed. It is only when biases are not corrected and a $1 \mathrm{~K}$ noise is imposed on $T_{b}$ that SSS is obtained with a better quality than the one retrieved in the best configuration $\left(30^{\circ}\right.$ incidence, V-polarization) with a single inversion. However, multiparametric retrievals with reasonable $T_{b}$ noise yield a better retrieved SSS than other retrievals over the period of RV Antea overflight, a period of highly variable wind speed, as they allow to improve the estimate of the wind speed itself.

In addition, this study demonstrates the value of the airborne remote sensing for giving a quasi instantaneous view of SSS at regional scale with better accuracy than SSS fields derived from coastal numerical model or OA. This particularly holds in very variable regions like the ones close to river plumes or shelf border where the numerical models may misestimate either the intensity or the position of the salinity gradients. We show the complementarity of in-situ measurements (very accurate but rarely coincident in space and time with the plane) and high-resolution oceanic models for interpreting the radiometric observations and sampling all the relevant phenomena in a coastal shelf area such as the one under study. Some variability observed close to the shelf edge by the radiometer was not sampled by the ship probably because of a time lag of one day between ship and plane measurements, but it was consistent with the IBI model SSS. Close to the Gironde plume where no in-situ measurement was available, the better agreement of the radiometric SSS with MARS 3-D model SSS than with IBI model SSS underlines the importance of using realistic river run-offs for modeling coastal SSS, as Mars 3-D model uses daily observed river run-offs whereas IBI model uses climatological river run-offs.

Although our results show the interest of L-band radiometry in coastal areas, the use of SMOS near the coast will require further study. Flights of our instrument further from the coast could be used to assess the performance of SMOS in coastal areas where contamination by the coast would be noticeable.

Further work using CAROLS data will deal with analyses of flights when concomitant observations of scatterometer data of
STORM and L-band radiometer data of CAROLS have been recorded. This will allow to eventually improve the modeling of the roughness impact in the SSS retrieval.

\section{ACKNOWLEDGMENT}

The authors wish to thank the crew of the RV Antea as well as the technical teams from SAFIRE and DT-INSU. The authors also thank D. Maurer for taking water samples during the Arcadino campaign, J. Mader for CTD from the AZTI ship, and Investigador, N. Martin for computation support. The authors also acknowledge Remote Sensing Systems for providing free and open access to Quick Scatterometer measurements.

\section{REFERENCES}

[1] D. Lorenz, E. Deweaver, and D. Vimont, "Evaporation change and global warming: The role of net radiation and relative humidity," J. Geophys. Res., vol. 115, p. D20 118, 2010. doi:10.1029/2010JD013949.

[2] K. Helm, N. Bindoff, and J. Church, "Changes in the global hydrologicalcycle inferred from ocean salinity," Geophys. Res. Lett., vol. 37, no. 18, p. L18 701, Sep. 2010.

[3] J. Font, A. Camps, A. Borges, M. Martin-Neira, J. Boutin, N. Reul, Y. Kerr, A. Hahne, and S. Mecklenburg, "SMOS: The challenging sea surface salinity measurement from space," Proc. IEEE, vol. 98, no. 5, pp. 649-665, May 2010.

[4] R. Schmitt, "Salinity and the global water cycle," Oceanography, vol. 21, no. 1, p. $12,2008$.

[5] S. Riser, L. ReN, and A. Wong, "Salinity in ARGO," Oceanography, vol. 21, no. 1, p. 56, 2008.

[6] G. Lagerloef, J. Boutin, Y. Chao, T. Delcroix, J. Font, P. Niiler, N. Reul, S. Riser, R. Schmitt, D. Stammer, and F. Wentz, "Resolving the global surface salinity field and variations by blending satellite and in situ observations," in Proc. OceanObs09-Sustained Ocean, Observations Information Society, J. Hall, D. E. Harrison, and D. Stammer, Eds., Venice, Italy, 2010, vol. 2, ESA Publication WPP-306.

[7] C. Swift and R. Mcintosh, "Considerations for microwave remote sensing of ocean-surface salinity," IEEE Trans. Geosci. Remote Sens., vol. GE-21, no. 4, pp. 480-491, Oct. 1983.

[8] G. Lagerloef, C. Swift, and D. LeVine, "Sea surface salinity: The next remote sensing challenge," Oceanography, vol. 8, no. 2, pp. 44-50, 1995.

[9] R. Lerner and J. Hollinger, "Analysis of $1.4 \mathrm{GHz}$ radiometric measurements from Skylab," Remote Sens. Environ., vol. 6, no. 4, pp. 251-269, 1977.

[10] G. Thomann, "Experimental results of the remote sensing of sea-surface salinity at 21-cm wavelength," IEEE Trans. Geosci. Electron., vol. GE-14, no. 3, pp. 198-214, Jul. 1976.

[11] H. Blume, B. Kendall, and J. Fedors, "Measurement of ocean temperature and salinity via microwave radiometry," Boundary-Layer Meteorol., vol. 13, no. 1, pp. 295-308, Jan. 1978.

[12] D. Le Vine, M. Kao, R. Garvine, and T. Sanders, "Remote sensing of ocean salinity: Results from the Delaware coastal current experiment," J. Atmos. Ocean. Technol., vol. 15, no. 6, pp. 1478-1484, Dec. 1998.

[13] J. Miller, M. Goodberlet, and J. Zaitzeff, "Airborne salinity mapper makes debut in coastal zone," EOS Trans., vol. 79, no. 14, p. 173, 1998.

[14] N. Fofonoff and R. Millard, Algorithms for Computation of Fundamental Properties of Seawater. Paris, France: UNESCO, 1983.

[15] D. Burrage, J. Wesson, M. Goodberlet, and J. Miller, "Optimizing performance of a microwave salinity mapper: STARRS L-band radiometer enhancements," J. Atmos. Ocean. Technol., vol. 25, no. 5, pp. 776-793, May 2008.

[16] D. Burrage, J. Wesson, C. Martinez, T. Perez, O. Moller, Jr, and A. Piola, "Patos Lagoon outflow within the Río de la Plata plume using an airborne salinity mapper: Observing an embedded plume," Continental Shelf Res., vol. 28 , no. 13, pp. 1625-1638, 2008.

[17] J. Kainulainen, K. Rautiainen, S. Tauriainen, T. Auer, J. Kettunen, and M. Hallikainen, "First 2-D interferometric radiometer imaging of the earth from an aircraft," IEEE Geosci. Remote Sens. Lett., vol. 4, no. 2, pp. 241 245, Apr. 2007

[18] M. Talone, R. Sabia, A. Camps, M. Vall-llossera, C. Gabarró, and J. Font, "Sea surface salinity retrievals from HUT-2D L-band radiometric measurements," Remote Sens. Environ., vol. 114, pp. 1756-1764, 2010. 
[19] Y. Kerr, P. Waldteufel, J. Wigneron, S. Delwart, F. Cabot, J. Boutin, M. Escorihuela, J. Font, N. Reul, C. Gruhier, S. E. Juglea, M. R. Drinkwater, A. Hahne, M. Martin-Neira, and S. Mecklenburg, "The SMOS mission: New tool for monitoring key elements of the global water cycle," Proc. IEEE, vol. 98, no. 5, pp. 666-687, May 2010.

[20] J. Font, J. Boutin, N. Reul, P. Spurgeon, A. Ballabrera, J. Gourrion, C. Hénocq, L. Samantha, N. Martin, J. Martínez, M. McCulloch, I. Meirold-Mautner, F. Petitcolin, M. Portabella, R. Sabia, M. Talone, J. Tenerelli, A. Turiel, J. L. Vergely, P. Waldteufel, X. Yin, S. Zine, and S. Delwart, "SMOS first data analysis for sea surface salinity determination," Int. J. Remote Sens., to be published.

[21] D. Le Vine, G. Lagerloef, and S. Torrusio, "Aquarius and remote sensing of sea surface salinity from space," Proc. IEEE, vol. 98, no. 5, pp. 688703, May 2010.

[22] M. Zribi, M. Parde, J. Boutin, P. Fanise, D. Hauser, M. Dechambre, Y. Kerr, M. Leduc-Leballeur, G. Reverdin, N. Skou, S. Søbjærg, C. Albergel, J. C. Calvet, J. P. Wigneron, E. Lopez-Baeza, A. Rius, and J. Tenerelli, "CAROLS: A new airborne L-band radiometer for ocean surface and land observations," Sensors, vol. 11, pp. 719-742, 2011.

[23] J. Rotbøll, S. Søbjæ, and N. Skou, "A novel L-band polarimetric radiometer featuring subharmonic sampling," Radio Sci., vol. 38, no. 3, p. 8046, 2003.

[24] S. Yueh, S. Dinardo, A. Fore, and F. Li, "Passive and active L-band microwave observations and modeling of ocean surface winds," IEEE Trans. Geosci. Remote Sens., vol. 48, no. 8, pp. 3087-3100, Aug. 2010.

[25] M. Parde, M. Zribi, P. Fanise, M. Dechambre, J. Boutin, N. Reul, J. Tenerelli, D. Hauser, and Y. Kerr, "Radio frequency interferences investigation using the airborne L-band full polarimetric radiometer CAROLS," in Proc. 11th Spec. Meeting IEEE MicroRad, 2010, pp. 300-305.

[26] P. Fanise, M. Pardé, M. Zribi, M. Dechambre, and C. Caudoux, "Analysis of RFI identification and mitigation in CAROLS radiometer data using a hardware spectrum analyser," Sensors, vol. 11, no. 3, pp. 3037-3050, 2011.

[27] N. Skou, S. Misra, J. Balling, S. Kristensen, and S. Sobjaerg, "L-band RFI as experienced during airborne campaigns in preparation for SMOS," IEEE Trans. Geosci. Remote Sens., vol. 48, no. 3, pp. 1398-1407, Mar. 2010.

[28] E. Daganzo, J. Pla, Y. Kerr, M. Martin-Neira, R. Oliva, E. Marelli, S. Mecklenburg, B. Rommen, M. Brown, P. Richaume, and C. Gruhier, "Characterisation of SMOS RF interferences in the 1400-1427 MHz band as detected during the commissioning phase," Revue de l'lectricit et de l'lectronique, vol. 4, pp. 18-29, 2011.

[29] G. Reverdin, L. M. P. Lazure, F. d'Ovidio, J. Boutin, P. Testor, N. Martin, A. Lourenco, F. Gaillard, A. Lavin, C. Rodriguez, R. Somavilla, J. Mader, A. Rubio, P. Blouch, J. Rolland, Y. Bozec, G. Charria, F. Batifoulier, F. Dumas, S. Louazel, and J. Chanut, "Fresh water from the Bay of Biscay shelves in 2009," J. Marine Syst., to be published. doi:10.1016/ j.jmarsys.2011.09.017.

[30] S. Cailleau, J. Chanut, B. Levier, C. Maraldi, and G. Reffray, "The new regional generation of Mercator Ocean system in the Iberian Biscay Irish (IBI) area," Mercator Q. Newslett., vol. 36, pp. 5-15, 2010.

[31] P. Lazure and A. Jégou, "3D modelling of seasonal evolution of Loire and Gironde plumes on Biscay Bay continental shelf," Oceanol. Acta, vol. 21, no. 2, pp. 165-177, 1998.

[32] J. Sibuet, S. Monti, B. Loubrieu, J. Mazé, and S. Srivastava, "Carte bathymétrique de 1 2019Atlantique nord-est et du golfe de Gascogne: Implications cinématiques," Bull. Soc. Géol., vol. 175, 2004.

[33] N. Reul, J. Tenerelli, B. Chapron, S. Guimbard, V. Kerbaol, and F. Collard, CoSMOS OS Campaign. Brest, France: IFREMER, Nov. 2006.

[34] N. Reul, J. Tenerelli, N. Floury, and B. Chapron, "Earth-viewing L-band radiometer sensing of sea surface scattered celestial sky radiation-Part II: Application to SMOS," IEEE Trans. Geosci. Remote Sens., vol. 46, no. 3, pp. 675-688, Mar. 2008.

[35] H. Liebe, G. Hufford, and M. Cotton, "Propagation modeling of moist air and suspended water/ice particles at frequencies below $1000 \mathrm{GHz}$," in AGARD, Atmospheric Propagation Effects Through Natural and ManMade Obscurants for Visible to MM-Wave Radiation. Boulder, CO: Nat. Telecommun. Inf. Admin., 1993, (SEE N94-30495 08-32).

[36] L. Klein and C. Swift, "An improved model for the dielectric constant of sea water at microwave frequencies," IEEE J. Ocean. Eng., vol. OE-25, no. 1, pp. 104-111, Jan. 1977.

[37] E. Dinnat, J. Boutin, G. Caudal, and J. Etcheto, "Issues concerning the sea emissivity modeling at L band for retrieving surface salinity," Radio Sci., vol. 38, no. 4, p. 8060, May 2003.

[38] J. Tenerelli, N. Reul, A. Mouche, and B. Chapron, "Earth-viewing L-band radiometer sensing of sea surface scattered celestial sky radiation-Part I:
General characteristics," IEEE Trans. Geosci. Remote Sens., vol. 46, no. 3, pp. 659-674, Mar. 2008.

[39] "SMOS L2 OS algorithm theoretical baseline document," ICM-CSIC, LOCEAN/LATMOS, IFREMER, Brest, France, Nov. 2008, Tech. Rep.

[40] S. Zine, J. Boutin, J. Font, N. Reul, P. Waldteufel, C. Gabarró, J. Tenerelli, F. Petitcolin, J. Vergely, M. Talone, and S. Delwart, "Overview of the SMOS sea surface salinity prototype processor," IEEE Trans. Geosci. Remote Sens., vol. 46, no. 3, pp. 621-645, Mar. 2008.

[41] C. Gabarro, M. Portabella, M. Talone, and J. Font, "Toward an optimal smos ocean salinity inversion algorithm," IEEE Geosci. Remote Sens. Lett., vol. 6, no. 3, pp. 509-513, Jul. 2009.

[42] R. Sabia, A. Camps, M. Talone, M. Vall-Llossera, and J. Font, "Determination of the sea surface salinity error budget in the soil moisture and ocean salinity mission," IEEE Trans. Geosci. Remote Sens., vol. 48, no. 4, pp. 1684-1693, Apr. 2010.

[43] M. Owen and D. Long, "Land contamination compensation for QuikSCAT near-coastal wind retrieval," IEEE Trans. Geosci. Remote Sens., vol. 47, no. 3, pp. 839-850, Mar. 2009.

[44] J. Boutin, N. Martin, X. Yin, N. Reul, and P. Spurgeon, "First assessment of SMOS measurements over open ocean: Part II sea surface salinity," IEEE Trans. Geosci. Remote Sens., submitted for publication.

[45] X. Yin, J. Boutin, and P. Spurgeon, "First assessment of SMOS measurements over open ocean: Part I Pacific Ocean," IEEE Trans. Geosci. Remote Sens., submitted for publication.

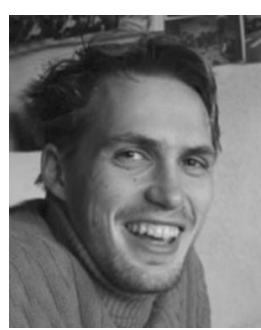

Adrien Martin (M'11) received the degree of telecommunications engineering from the French Graduate Engineering School Telecom Bretagne, Brest, France, in 2009. He is currently working toward the Ph.D. degree in microwave remote sensing at the Laboratoire d'Océanographie et de Climatologie par Expérimentation et Analyse Numérique, Institut Pierre Simon Laplace, University Pierre et Marie Curie, Paris, France.

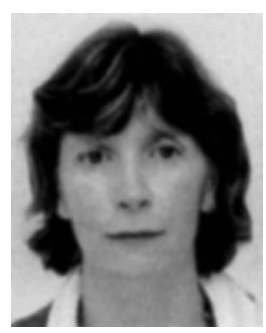

Jacqueline Boutin received the $\mathrm{Ph} . \mathrm{D}$. degree in physical methods in remote sensing from the University Paris VII, Paris, France, in 1990.

She is currently a Research Scientist at the Centre National de la Recherche Scientifique in the Laboratoire d'Océanographie et du ClimatExpérimentation et Approches Numériques, Paris. She has widely studied the validity of remotely sensed wind speeds and the ocean/atmosphere exchange of $\mathrm{CO} 2$ at large scale using both satellite (wind speeds, sea surface temperature, and ocean color) and in-situ data (in particular, carbon-interface ocean-atmosphere autonomous drifters, CARIOCA). Since 1999, she has been involved in the preparation of the Soil Moisture and Ocean Salinity (SMOS) mission. She participated in the development of an L-band sea surface emissivity model and in several airborne campaigns (WISE and Eurostarrs). She is a member of the European Space Agency Expert Support Laboratories that define and validate the processing of SMOS Level 2 measurements for the retrieval of sea surface salinity.

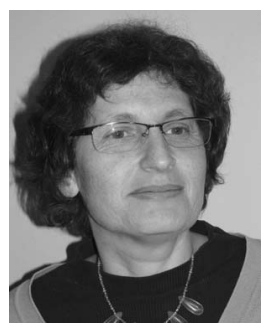

Danièle Hauser received the Ph.D. degree in physics from Université Pierre et Marie Curie, Paris, France, in 1980.

Until 1990, she has been working as a Researcher on cloud physics based on remote sensing techniques (Doppler meteorological radar). She is today Senior Scientist of the Centre National de la Recherche Scientifique. Since the 1990s, her main field of research is on physics of the ocean surface, and air/sea interactions, using preferentially remote sensing methods (active and passive microwave observations). She is currently Principal Investigator of two airborne radar instruments (STORM and KuROS) designed for the measurement of ocean surface wind and waves, and also Co-Principal Investigator of the China France Oceanographic Satellite which also embarks two radar for wind and wave observations (to be launched in 2014). Since 2009, she is also Director of the laboratory "LATMOS." 


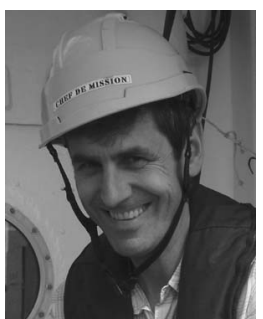

Gilles Reverdin got his These de 3eme cycle in 1980 on the Indian monsoon low level circulation.

$\mathrm{He}$ then worked partly at the Laboratoire d'Océanographie Physique in Paris and at the Massachusetts Institute of Technology on the Indian Ocean surface equatorial currents, and defended his These d'état in 1985. He then worked until the 1990 at the Laboratoire d'Océanographie et de Climatologie par Expérimentation et Analyse Numérique (LOCEAN) in Paris on the upper layers of the equatorial Atlantic and equatorial Pacific, both from in-situ data and model simulations. From 1990 to 1994, he was at the LamontDoherty Earth Observatory (Columbia Univesity, USA) working on the upper ocean role on climate variability, and in sampling from merchant vessels or drifters the surface layer of the ocean. In particular, he got interested in salinity variability during the last hundred years. Since 1995, he has been an oceanographer in France (first at LEGOS, Toulouse, then LOCEAN Paris) interested in upper ocean variability at small, meso, and large scales for a range of issues, mostly of circulation and climate, but also on biogeochemical cycles and proxy observations. He is in charge of research and development of the Coriolis project and in coordinating the research in situ oceanographic observatory (CTDO2). He continues sea-going work, and had the pleasure to be Chief Scientist of different cruises, lately of the Gogasmos cruise in May 2009, as well as contributing to the development of drifters measuring precisely nearsurface ocean salinity.

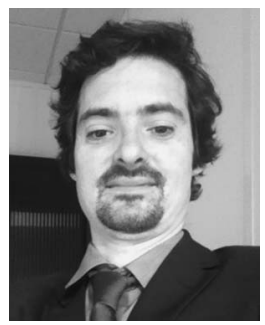

Mickaël Pardé received the M.S. degree in remote sensing and the Ph.D. degree in "méthodes physiques en télédétection" from the Université Denis Diderot (Paris 7), Paris, France, in 1999 and 2003, respectively.

Between 2000 and 2003, he was with the Institut National de Recherche Agronomique (INRA), Avignon, France, and with INRA, Bordeaux, France, on the vegetation effects on the radiometric signal in the framework of the Soil Moisture and Ocean Salinity project. In 2004, he was a Postdoctoral Researcher with the Centre d'Applications et de Recherches en Télédétection Laboratory, Université de Sherbrooke, Sherbrooke, QC, Canada, and worked on the estimation of snow-water equivalent using satellite measurements of surface microwave emission. Since 2007, he has been with the Laboratory ATmosphere, Milieu, and Spatial Observations, Guyancourt, France, on airborne brightness temperature measurements of surface. His interest includes surface-parameter estimation using passive and radar microwave remote sensing, mainly in the context of hydrology.

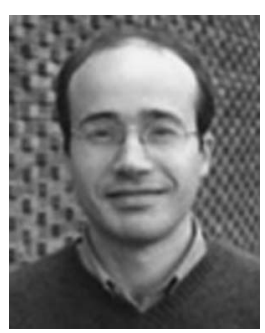

Mehrez Zribi received the engineering degree in signal processing from the Ecole Nationale Supérieure d'Ingénieurs en Constructions Aéronautiques, Toulouse, France, and the Ph.D. degree from the Université Paul Sabatier, Toulouse, France.

In 1995, he joined the Centre d'étude des Environnements Terrestre et Planétaires laboratory (IPSL/ CNRS), Vélizy, France. He is employed by Centre National de Recherche Scientifique, since 2001. In October 2008, he joined the Centre d'Etude Spatial de la BIOsphère laboratory and Institut de Recherche pour le Développement. His research interests include microwave remote sensing applied to hydrology and microwave modeling and instrumentations.

Pascal Fanise, photograph and biography not available at the time of publication.

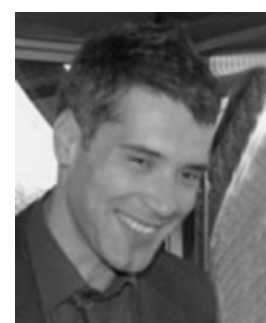

Jérôme Chanut received the engineering degree in signal processing from the Institut National Polytechnique, Grenoble, France, in 1999.

Then, he joined the Laboratoire des Ecoulements Géophysiques et Industriels in Grenoble and received a Ph.D. degree in geophysical fluids dynamics from the Joseph Fourier University in Grenoble, France, in 2003. His research dealt with large-scale numerical modeling in the subpolar gyre and the impact of mesoscales in deep convection processes. $\mathrm{He}$ is currently with Mercator Océan in Toulouse where he is involved in the development of high-resolution regional ocean forecasting systems and the management of related activities in European projects.

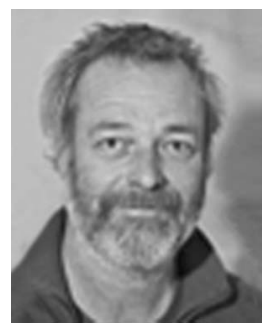

Pascal Lazure received the B.S. degree in physical oceanography from Brest university in 1983.

From 1987, he has been working at the Institut Frans de Recherche pour l'Exploitation de la Mer as a Research Scientist. He developed the Mars 3-D model which is used for coastal applications. For the last four years, he has been involved in observation programs of the continental shelf of the Bay of Biscay.

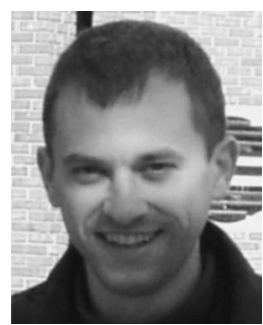

Joseph Tenerelli received the B.S. degree in atmospheric sciences from the University of Washington, Seattle, in 1994.

From 1999 to 2005, he was a Research Associate at the Rosenstiel School of Marine and Atmospheric Science, University of Miami, Coral Gables, FL, where he worked as part of a team to develop a coupled atmosphere-ocean-surface wave model with vortex-following mesh refinement suitable for simulating hurricanes. In April 2005, he joined the Institut Français de Recherche pour l'Exploitation de la Mer, Brest, France, as a Research Engineer working as part of a team developing an algorithm to retrieve sea surface salinity from L-band radiometric measurements (the European Space Agency's Soil Moisture and Ocean Salinity (SMOS) project). Since 2008, he has continued his work on the SMOS mission as a Research Engineer within the Radar Division of Collecte Localisation Satellites.

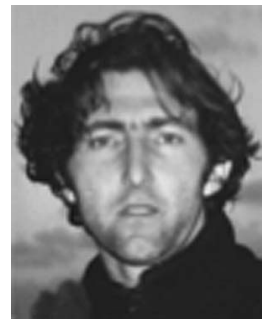

Nicolas Reul received the B.S. degree in marine science engineering from Toulon University, La Garde, France, in 1993, and the Ph.D. degree in physics (fluid mechanics) from the University of Aix-Marseille II, Marseille, France, in 1998.

From 1999 to 2001, he worked as a Postdoctoral Researcher with the Applied Marine Physics Department, Rosenstiel School of Marine and Atmospheric Science, University of Miami, Coral Gables, FL. Since 2001, he has been a Research Scientist with the Spatial Oceanography Group, Institut Français de Recherche pour l'Exploitation de la Mer, Plouzané, France, where he is responsible for the activities concerning the Soil Moisture and Ocean Salinity (SMOS) satellite mission. The focus of his research program is to improve the understanding of the physical processes at air-sea interface and passive/active remote sensing of the ocean surface. He has experience in applied mathematics, physical oceanography, electromagnetic wave theory, and its application to ocean remote sensing. He is currently a member of the European Space Agency/SMOS Quality Working Group. 